\title{
Factors influencing the acceptance of HPV vaccine among civil servants in Delta State Secretariat
}

\author{
Uchechukwuka Nnemdi Okwe ${ }^{1}$, Helen Chime ${ }^{2}$, Ezekiel Uba Nwose ${ }^{2 *}$
}

\author{
${ }^{1}$ Delta State Secretariat Clinic, Asaba, Nigeria \\ ${ }^{2}$ Department of Public and Community Health, Novena University, Ogume, Nigeria
}

Received: 08 February 2019

Accepted: 06 March 2019

\section{*Correspondence:}

Dr. Ezekiel Uba Nwose,

E-mail: enwose@csu.edu.au

Copyright: ( $\odot$ the author(s), publisher and licensee Medip Academy. This is an open-access article distributed under the terms of the Creative Commons Attribution Non-Commercial License, which permits unrestricted non-commercial use, distribution, and reproduction in any medium, provided the original work is properly cited.

\begin{abstract}
Background: The importance of cervical screening and HPV vaccination cannot be overemphasized. Yet, the level of uptake of HPV vaccination has never been evaluated among Secretariat personnel in Delta State of Nigeria. This partof-four piece of study aimed to identify the barriers to the acceptance of HPV vaccination in Delta State, Nigeria.

Methods: A cross-sectional, descriptive survey method was adopted using a structured questionnaire. 285 participants were included. The structured questionnaire included questions on acceptance of HPV vaccination and the factors influencing acceptability. Statistical analysis included percentage proportions of respondents. Absolute and relative frequencies of the factors were also determined. Chi-squared analysis was performed based on dichotomy of participants based on yes/no response to being vaccinated.

Results: Less than $8 \%$ of respondents have completed the HPV vaccination program. Low income earners have accepted the vaccination more than the high income group $(\mathrm{p}<0.003)$. Nature of work implying time constraints was an absolute factor. Accessibility is one of four factors that were significantly associated $(p<0.002)$.

Conclusions: Given the observation on nature of work and associated implication of time constraints and also inaccessibility as potentially major factors; it suffices to suggest that acceptance of HPV vaccination may be improved by expounding the days and sites of vaccination programs to be closer to the offices and scheduled around lunch-break times.
\end{abstract}

Keywords: HPV vaccination, Inaccessibility, Nature of work, Psychosocial barriers, Women

\section{INTRODUCTION}

Human papilloma virus (HPV) infection is the causative risk factor of cervical cancer and HPV vaccines are given as a preventive measure. It is given to women who have been exposed to sex and have negative Pap smear or cervical screen results. HPV is ubiquitous and virginal sexual intercourse constitutes a risk of infection. As long as a female eventually has sex with another person, she is likely to be exposed to HPV infection. ${ }^{1,2}$ It is better therefore to have been vaccinated against the HPV strains mostly associated with cervical cancer. ${ }^{3}$
The popular saying that prevention is better than cure should be applicable since Nigeria is not an exception to the increase in sexual permissiveness. Data from National Nigerian demographic and health Survey shows that the median age at first sexual intercourse in Nigeria is 16 years, which corresponds very well to the peak age incidence of HPV being adolescents or below 25years. ${ }^{4,5}$ This underscores the relevance of ensuring HPV vaccination of young women in Nigerian communities. ${ }^{6}$

The acceptability of the vaccines is defined as the willingness of an individual to be vaccinated. This is a 
factor that contributes to its uptake. Barriers at personal, community and provider level may inhibit the translation of willingness to have cervical cancer prevention services, which include HPV vaccination. Probably foremost among the factors are psychosocial barriers such as affordances, beliefs, fears, and sociocultural constraints, amongst others. ${ }^{7-10}$ For instance, discussion around HPV vaccination noted in:

- United States of America-that cultural sensitivity among Muslim women is necessary strategy to improve acceptance. ${ }^{10}$

- Gwagwalada of Nigeria-low level of knowledge about HPV vaccination and perception that cervical cancer is not preventable were major barriers. ${ }^{11}$

- Canada-a publicly funded HPV vaccination program was disallowed at a Catholic school based on belief that the exercise would send a wrong message of early sexual intercourse being allowed. ${ }^{12}$

- Thailand-parents' beliefs and knowledge level were reported to influence acceptance of HPV vaccination. $^{13}$

Delta State is located at the coastal region bound on the south by Atlantic Ocean and composed of a microcosm of multiple social cultures. There are lots of oil exploration activities with associated immigrant employees allowing for high level of sexual activities, hence the importance of cervical screening and HPV vaccination cannot be overemphasized. ${ }^{14}$ Yet, the level of acceptance of HPV vaccination has neither been evaluated, nor the prevailing factors influencing the female civil servants who visit the Delta State Secretariat clinic determined. Therefore, a study to identify the barriers to the acceptance of HPV vaccination in Delta State is pertinent. Further, the female civil servants in Delta State Ministries cut across all educational classes, cultural groups, different reproductive age groups and all professions i.e. works of life. Their opinion will apparently represent the view of women generally. Therefore, it is pertinent to assess the factors influencing HPV vaccination using the female civil servants.

\section{METHODS}

This was the second of four pieces of work in the series of study. It was designed to be a cross sectional, descriptive survey method. The study setting was the Delta State Secretariat Clinic located in Asaba, the State capital (Approval Reference: HD 92/A/28 Ministry of Health).

Four hundred and fifteen (415) questionnaires were distributed, out of which 285 were satisfactorily completed and included for analysis. Consent and voluntarism were assumed on return of the completely filled forms. Therefore, others did not submit, were incompletely filled, or were returned unfilled.
Questionnaire survey was used to collect data on eight demographic factors, which were analyzed as part one in this series of work. The structured questionnaire for this part of the series consisted of two sections as follows:

Section E: four (4) questions used to assess the acceptance of HPV vaccination as well as willingness to vaccinate.

Section G: thirteen (13) questions on possible factors influencing acceptability of HPV vaccination.

\section{Statistical analysis}

The data collected were field edited daily on a spread sheet and statistical package for social sciences (SPSS version 21 was used for analysis). Statistical analysis included percentage proportions of respondents. Absolute and relative frequencies of the psychosocial factors were also determined. Chi-squared analysis was performed based on dichotomy of participants who either had undertaken or yet to undertake cervical screening.

\section{RESULTS}

Analysis of acceptance of HPV vaccination show that $7.4 \%$ of the ' $\mathrm{N}=285$ ' women in this study have had the vaccines and completed the dose. Among the 264 who indicated to 'No' to been vaccinated comprised, 259 have willingness to vaccinate later, and 257 of them had previously commenced vaccination but never completed it while 249 intends to complete the otherwise incomplete procedure. $97.5 \%$ of all the ' $\mathrm{N}=285$ ' respondents agreed to encourage their daughters to have the vaccine (Table $1)$.

Table 1: Acceptance of and willingness to accept HPV vaccination.

\begin{tabular}{|l|l|l|l|l|}
\hline $\begin{array}{l}\text { Questions } \\
\text { Have you been } \\
\text { vaccinated with HPV }\end{array}$ & 21 & 7.4 & 264 & 92.6 \\
\hline $\begin{array}{l}\text { vaccine } \\
\text { If No will you be } \\
\text { vaccinated later }\end{array}$ & 259 & 98.1 & 5 & 1.9 \\
\hline $\begin{array}{l}\text { If dosage is incomplete } \\
\text { will you complete }\end{array}$ & 249 & 96.9 & 8 & 3.1 \\
\hline $\begin{array}{l}\text { Will you encourage } \\
\text { someone to take }\end{array}$ & 278 & 97.5 & 7 & 2.5 \\
\hline
\end{tabular}

Analysis of responses to questions on factors influencing acceptance of HPV vaccination indicate that all respondents $(\mathrm{N}=285)$ agree that religion does not forbid them from taking the vaccine (Table 2).

Among other factors, nature of work has the highest relative influence, while discouragement, fear of stigma and community taboo constitute the least three influential factors (Figure 1). 
Table 2: Responses to factors influencing acceptance of HPV vaccination.

\begin{tabular}{|c|c|c|c|c|}
\hline Possible psychosocial factors & $\mathbf{Y}$ & $\mathbf{Y} \%$ & $\mathbf{N}$ & $\mathbf{N} \%$ \\
\hline Unaffordable cost of HPV Vaccine & 262 & 91.9 & 23 & 8.1 \\
\hline Fear of discomfort/pain of the HPV injection & 238 & 83.5 & 47 & 16.5 \\
\hline Fear of adverse effect of HPV vaccine & 193 & 67.7 & 92 & 32.3 \\
\hline Inaccessibility to sites for HPV Vaccine & 230 & 80.7 & 55 & 19.3 \\
\hline Fear of lack of privacy and confidentiality & 125 & 43.9 & 160 & 56.1 \\
\hline Lack of support from spouse to take vaccine & 107 & 37.5 & 178 & 62.5 \\
\hline Discouraged by colleagues & 13 & 4.6 & 272 & 95.4 \\
\hline Religion forbids HPV vaccination & - & - & 285 & 100 \\
\hline Community taboo towards taking the vaccine & 2 & 0.7 & 283 & 99.3 \\
\hline Nature of work will not allow taking vaccine & 283 & 99.3 & 2 & 0.7 \\
\hline Attitude of health workers puts me off & 172 & 60.4 & 113 & 39.6 \\
\hline Don't believe in vaccine for prevention & 20 & 7 & 264 & 92.6 \\
\hline Fear of being stigmatized & 6 & 2.1 & 279 & 97.9 \\
\hline
\end{tabular}

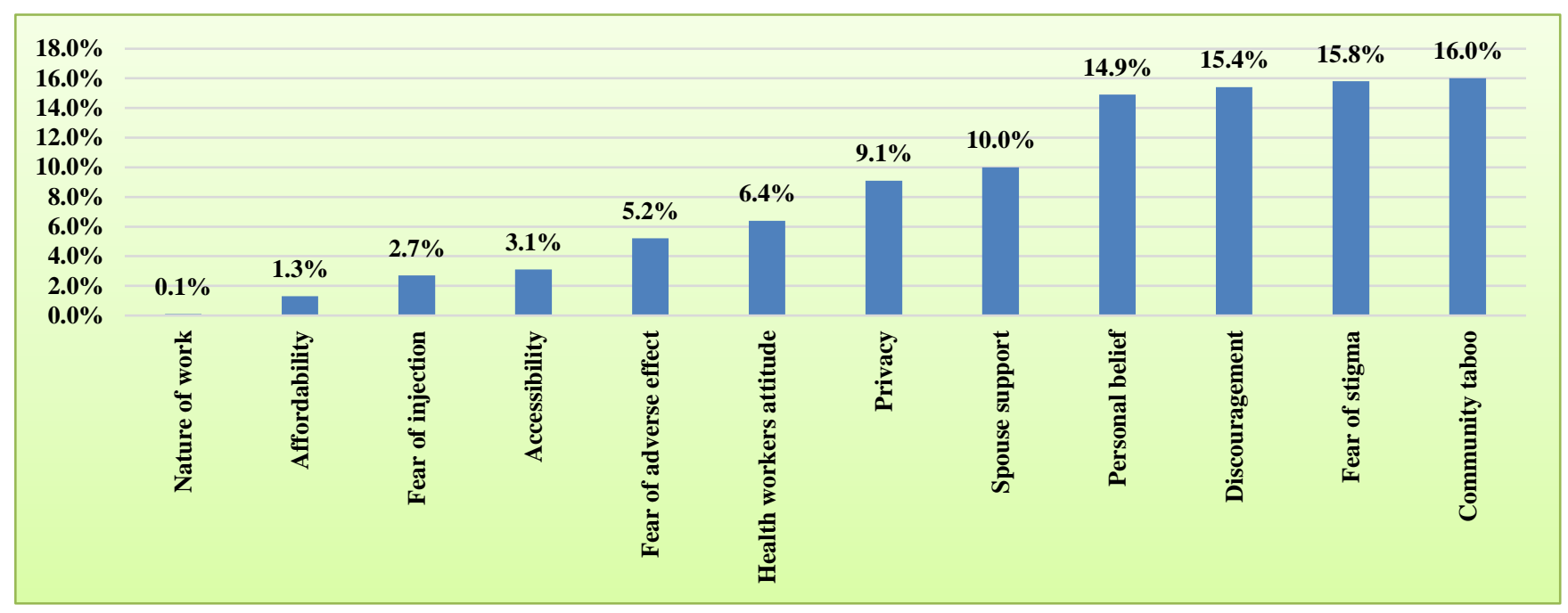

Figure 1: Relative frequencies of 'No' responses to factors.

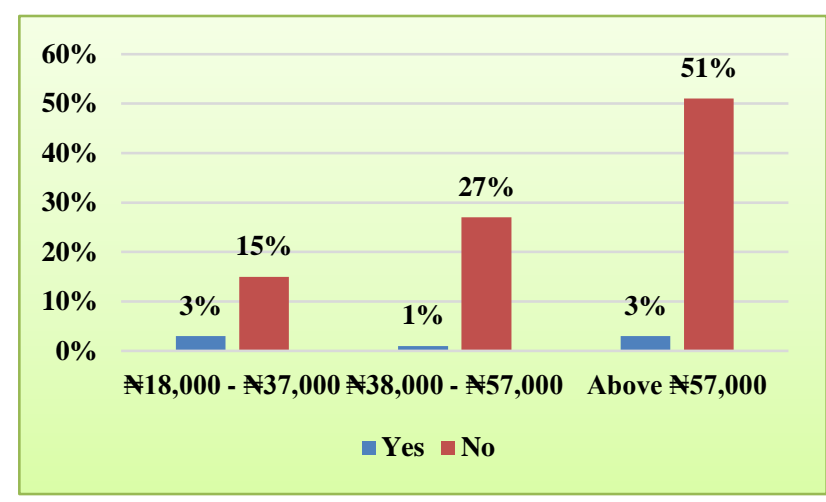

Figure 2: Relative frequencies out of $100 \%$ (responses of stratified income groups).

Initial stratification of respondents into income groups and subsequent evaluation of cervical screening plus HPV screening show that acceptance was not different between relative frequencies of income groups, whereas 'No' responders linearly increased with monthly income.

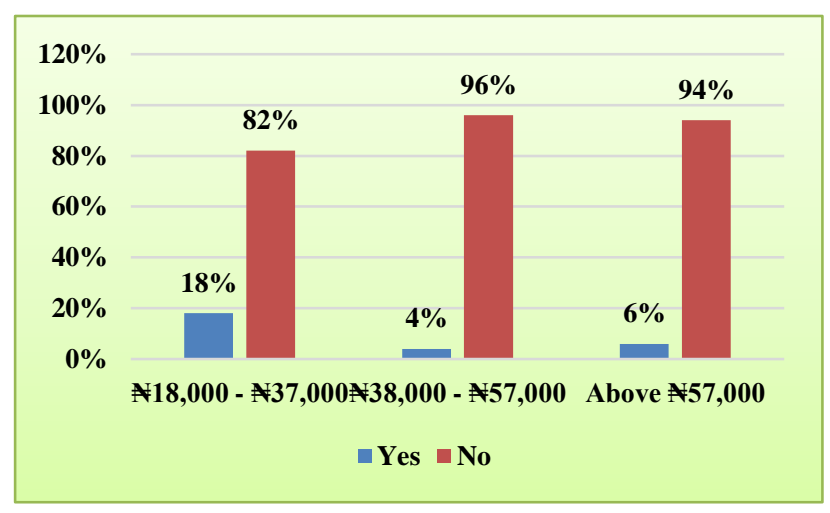

Figure 3: Absolute frequencies within income subgroups (responses of stratified income groups).

Evaluation of proportion of each income groups show higher percentage of lowest income earners accepted the vaccine (Figure 2 and 3). Chi square test show statistics to be significant 'No' responses $(\mathrm{p}<0.05)$. 
Further evaluation indicates that there are some psychosocial factors like inaccessibility of vaccine sites, attitude of health workers put me off vaccination, lack of support from spouse to undergo vaccination, fear of lack of privacy and confidentiality with negative associations on the uptake of human papilloma vaccination by the female civil servants (Table 3 ).

Table 3: Chi square output psychosocial barriers vs being vaccinated $(\mathrm{N}=\mathbf{2 8 5})$.

\begin{tabular}{|c|c|c|c|c|c|}
\hline \multicolumn{2}{|l|}{ Psychosocial factors } & Yes & No & $\mathrm{Chi}^{2}$ & P value \\
\hline \multirow{2}{*}{ Unaffordable cost of vaccine HPV } & Yes & 20 & 242 & & \\
\hline & No & 1 & 22 & 0.33 & 0.57 \\
\hline \multirow{2}{*}{ Inaccessibility of vaccine sites } & Yes & 6 & 224 & & \\
\hline & No & 15 & 40 & 35.56 & 0.002 \\
\hline \multirow{2}{*}{ Fear of adverse effect of vaccines } & Yes & 17 & 176 & & \\
\hline & No & 4 & 88 & 1.82 & 0.17 \\
\hline \multirow{2}{*}{ Fear of discomfort of pain injections } & Yes & 21 & 236 & & \\
\hline & No & 0 & 28 & 2.47 & 0.12 \\
\hline \multirow{2}{*}{ Lack of privacy } & Yes & 4 & 121 & & \\
\hline & No & 7 & 153 & 5.67 & 0.02 \\
\hline \multirow{2}{*}{ Lack of support from spouse } & Yes & 1 & 106 & & \\
\hline & No & 20 & 158 & 10.39 & 0.001 \\
\hline \multirow{2}{*}{ Discouraged by friends to undergo vaccination } & Yes & 0 & 13 & & \\
\hline & No & 21 & 251 & 1.08 & 0.29 \\
\hline \multirow{2}{*}{ Family or community taboo against vaccine } & Yes & 0 & 2 & & \\
\hline & No & 21 & 262 & 0.16 & 0.69 \\
\hline \multirow{2}{*}{ Schedule of work will not allow vaccine taking } & Yes & 21 & 262 & & \\
\hline & No & 0 & 2 & 0.16 & 0.69 \\
\hline \multirow{2}{*}{ Attitude of health workers put me off } & Yes & 8 & 164 & & \\
\hline & No & 13 & 100 & 4.69 & 0.03 \\
\hline \multirow{2}{*}{ Don't believe HPV vaccination is preventive } & Yes & 0 & 225 & & \\
\hline & No & 20 & 40 & 1.63 & 0.20 \\
\hline \multirow{2}{*}{ Fear of stigmatization } & Yes & 0 & 6 & & \\
\hline & No & 21 & 258 & 0.49 & 0.48 \\
\hline
\end{tabular}

\section{DISCUSSION}

This study aimed to assess the factors influencing acceptance of HPV vaccination among female civil servants in Delta State's capital city of Asaba. The initial background evaluation of demographics and knowledge level indicated that virtually all women in the scoped population may have heard of cervical cancer and knows that sexual promiscuity is a risk of the health condition. However, approximately $6 \%$ of the participants are unaware that susceptibility to HPV causes it, while a much higher proportion $(57 \%)$ knows the methods of prevention. For this particular discourse, the assessment of acceptance level of HPV vaccination only 21 out of 285 respondents have been vaccinated. Among those (264 out of 285) who are unvaccinated, 98\% (259 out of 264) are willing to vaccinate. 257 appeared to have previously commenced but never completed the vaccination and $3 \%$ of this subpopulation are unwilling to complete it. It is also observed that $2.5 \%$ ( 7 out of 285 ) of the participants are unwilling to recommend someone e.g. their daughter to take up the vaccination (Table 1). On reflection, it was noted among the 259/264 who indicated to vaccinate later that not all of them agreed to encourage their daughters to take up the vaccination. In other words, there is still some confounders to the willingness level. It is inferred that these confounders may be psychosocial factors and probably responsible for the $3 \%$ of subpopulation who did not complete the vaccination process they commenced and are unwilling to complete it.

Nevertheless, it must be emphasized that only approximately $7 \%$ have vaccinated, but over $97 \%$ are willing to vaccinate later and/or encourage others to take up the vaccine. This observation is in agreement with the recent report from Thailand, which highlighted that parents' beliefs and knowledge level influence acceptance of HPV vaccination. ${ }^{13}$ That is, improvement in level of knowledge of mothers about HPV can be attributed for the high willingness to vaccinate later and encourage others e.g. daughters to take up the vaccine. Regarding the factors that influence acceptance, $99 \%$ of respondents agreed that nature of work is a factor thereby constituting the greatest possible influence. Approximately $92 \%$ indicated unaffordable cost, which 
takes the second position. Another major factor was inaccessibility of the vaccines in most hospitals, which ranks fourth after 'fear of discomfort or pain' in the third position (Table 2). Considering that most vaccines are given in major HPV screening sensitization programs in the State and which are not continuous; this high level of indication of affordances (i.e. accessibility and affordability) implies a need to improve the public health announcements about the programs. Quite importantly, if civil servants in the State's capital city designates affordances as a limiting factor, it is thinkable "what could be the hope of unemployed women living in rural community?' This opinion is supported by knowledge that high- and low-income status respectively constitutes a promoter and barrier to vaccination. ${ }^{15}$

Nevertheless, a reverse evaluation of the psychosocial factors in terms of 'No' influence show that religion is outstanding as all (100\%) of the respondents indicated that religion does not forbid HPV vaccination (Table 2). Among the remaining twelve factors in the questionnaire, community taboo ranks topmost followed by fear of stigma as psychosocial factors with 'No' or may not influence HPV vaccination uptake (Figure 2). If the data present in figure two is further critically reviewed, data show that low income earners appear to take up HPV vaccination more than the high income earners. This observation may confound the socioeconomic status being a barrier. However, it is known that time pressure is one of several other barriers to uptake of vaccinations. ${ }^{16}$ It is pertinent to recall that nature of work constitute the greatest barrier identified among respondents in this study. Therefore, it can be inferred that the female civil servants in the Delta State are experiencing time pressure as one of their barriers to accepting HPV vaccination. This is in agreement with recent report from Canada that taking time off work to go for cervical services is an economic barrier. ${ }^{17}$

The maternal level of education was identified to be associated with level of uptake in a study in Hong Kong. ${ }^{18}$ Also in a study in Germany, there was low uptake because the vaccine was for the lower age group of 8 to 26 years who have not been exposed to sex and mainly given to adolescents. ${ }^{19}$ The refusal in uptake in the study was as a result of HPV safety, side effects and many claimed it was too time consuming as there were three doses taken every two months. There are concerns that the vaccine is an introduction of the HPV infection. The concerns of spouses were that wives may not benefit from it since they have been exposed to sex. This view was also implored in the report from Vietnam. ${ }^{20}$ For the acceptance to be increased, the health workers need to improve their communication skills and educate mothers on the importance of the vaccine for their adolescent girl child, families, communities and health care providers. Evaluation of statistical significance show that there is obviously an association of several psychosocial factors in the acceptance of HPV vaccination among the female civil servants in Delta State, Nigeria. Using the 0.05 level of significance and the Chi square cross tabulation (Table 3 ), some of these psychosocial factors and their associations were seen in attitude of health workers ( $p$ $<0.003)$, inaccessibility of the vaccines $(p<0.002)$, lack of privacy $(\mathrm{p}<0.002)$ and lack of support from their husbands with respect to taking the vaccine $(\mathrm{p}<0.001)$. A lot of females do not believe that stigmatization, cost of the vaccine, presumed adverse effect of HPV vaccine, and discomfort of the vaccine dissuaded from them HPV vaccination; but these did not achieve statistical significance.

Discussions on psychosocial barriers between patients and health professionals involved in cervical cancer screening and HPV vaccination might increase uptake and thus reduce cervical cancer mortality rates. Communication skills, training of health professionals conducting the screen might focus on the most frequently reported barriers and emotions related to screening and vaccination. This observation is agreement with known factors reported from other studies. ${ }^{16,17}$

It had been reported that the future of cervical services in Europe would need to be diversified. ${ }^{21}$ In Nigeria, a clarion call for well-planned and implemented program has been made, and the need for cost-effectiveness was recently emphasized. ${ }^{22}$ Given the observation on nature of work and associated implication of time constraints and also inaccessibility as potentially major psychosocial factors; it suffices to suggest that uptake of HPV vaccination may be improved by expounding the sites of vaccination programs to be closer to the offices and scheduled around lunch-break times as well as for days per site in order to provide options. This suggestion is based on the backdrop that the problem of time goes beyond lack of time at individual level to include long waiting time at the healthcare system level.

\section{CONCLUSION}

This study investigated the level of acceptance and factors of HPV among women who are civil servants cum clients of the Secretariat clinic in the state's capital city. Results show that acceptance of the vaccination is low, especially with less than $8 \%$ of respondents having completed the process. There is obviously an association of several factors, notably inaccessibility and nature of work, in the acceptance of HPV vaccination among the female civil servants in Delta State, Nigeria.

\section{ACKNOWLEDGMENTS}

Authors would like to thank staff of the Delta State Secretariat clinic, especially nurses, were helpful in data collection and are hereby appreciated.

\author{
Funding: No funding sources \\ Conflict of interest: None declared \\ Ethical approval: The study was approved by the \\ Institutional Ethics Committee
}




\section{REFERENCES}

1. Burchell AN, Rodrigues A, Moravan V, Tellier PP, Hanley J, Coutlee F, et al. Determinants of prevalent human papillomavirus in recently formed heterosexual partnerships: a dyadic-level analysis. J Infect Dis. 2014;210(6):846-52.

2. de Koning MN, Quint KD, Bruggink SC, Gussekloo J, Bouwes Bavinck JN, Feltkamp MC, et al. High prevalence of cutaneous warts in elementary school children and the ubiquitous presence of wartassociated human papillomavirus on clinically normal skin. Br J Dermatol. 2015;172(1):196-201.

3. Gravitt PE, Jamshidi R. Diagnosis and management of oncogenic cervical human papillomavirus infection. Infect Dis Clin North Am. 2005;19(2):43958.

4. Yaya S, Bishwajit G. Age at first sexual intercourse and multiple sexual partnerships among women in Nigeria: A cross-sectional analysis. Front Med (Lausanne). 2018;5:171.

5. Smith JS, Melendy A, Rana RK, Pimenta JM. Agespecific prevalence of infection with human papillomavirus in females: a global review. J Adolesc Health. 2008;43(4 Suppl):S5-25,S25.e2141.

6. Balogun F, Omotade O: "She must have been sleeping around"...: Contextual interpretations of cervical cancer and views regarding HPV vaccination for adolescents in selected communities in Ibadan, Nigeria. PLoS One 2018;13(9):e0203950.

7. Aboyeji PA, Ijaiya M-DA, Jimoh A-GA. Knowledge, attitude and practice of cervical cancer as screening procedure for cervical cancer in Ilorin, Nigeria. Trop J Obstet Gynaecol. 2004;21(2):114-7.

8. Assoumou SZ, Mabika BM, Mbiguino AN, Mouallif M, Khattabi A, Ennaji MM. Awareness and knowledge regarding of cervical cancer, Pap smear screening and human papillomavirus infection in Gabonese women. BMC Womens Health 2015;15:37.

9. Ayinde OA, Ogunbode OO, Adebayo OJ. Determinants of cervical cancer knowledge and its utilization of screening among a Nigerian female population. Trop J Obstet Gynaecol. 2005;22(1):214.

10. Guimond ME, Salman K. Modesty matters: cultural sensitivity and cervical cancer prevention in muslim women in the United States. Nurs Womens Health. 2013;17(3):210-6.

11. Nnodu O, Erinosho L, Jamda M, Olaniyi O, Adelaiye R, Lawson $\mathrm{L}$, et al. Knowledge and attitudes towards cervical cancer and human papillomavirus: a Nigerian pilot study. Afr J Reprod Health. 2010;14(1):95-108.

12. Guichon JR, Mitchell I, Buffler P, Caplan A. Citizen intervention in a religious ban on in-school HPV vaccine administration in Calgary, Canada. Prev Med. 2013;57(5):409-13.

13. Grandahl M, Paek SC, Grisurapong S, Sherer P, Tyden T, Lundberg P. Parents' knowledge, beliefs, and acceptance of the HPV vaccination in relation to their socio-demographics and religious beliefs: A cross-sectional study in Thailand. PLoS One 2018;13(2):e0193054.

14. Nwauche CA, Akani CI. An assessment of high risk sexual behaviour and HIV transmission among migrant oil workers in the Niger Delta area of Nigeria. Niger J Clin Pract. 2006;9(1):48-51.

15. Vorsters A, Arbyn M, Baay M, Bosch X, de Sanjose $S$, Hanley S, et al. Overcoming barriers in HPV vaccination and screening programs. Papillomavirus Res. 2017;4:45-53.

16. Waller J, Jackowska M, Marlow L, Wardle J. Exploring age differences in reasons for nonattendance for cervical screening: a qualitative study. BJOG. 2012;119(1):26-32.

17. Ferdous M, Lee S, Goopy S, Yang H, Rumana N, Abedin $\mathrm{T}$, et al. Barriers to cervical cancer screening faced by immigrant women in Canada: a systematic scoping review. BMC Womens Health. 2018;18(1):165.

18. Loke AY, Chan ACO, Wong YT. Facilitators and barriers to the acceptance of human papillomavirus (HPV) vaccination among adolescent girls: a comparison between mothers and their adolescent daughters in Hong Kong. BMC Res Notes 2017;10(1):390.

19. Stocker P, Dehnert M, Schuster M, Wichmann O, Delere Y. Human papillomavirus vaccine uptake, knowledge and attitude among 10th grade students in Berlin, Germany, 2010. Hum Vaccin Immunother. 2013;9(1):74-82.

20. Breitkopf CR, Pearson HC, Dinh TA, Tran BC, Vu $\mathrm{T}$, Phan GA, et al. Human papillomavirus vaccine decision-making in Da Nang, Vietnam: perceived spousal and adolescent-parent concordance. Vaccine 2009;27(17):2367-71.

21. Lynge E, Antilla A, Arbyn M, Segnan N, Ronco G. What's next? Perspectives and future needs of cervical screening in Europe in the era of molecular testing and vaccination. Eur $\mathrm{J}$ Cancer. 2009;45(15):2714-21.

22. Ekwunife OI, Lhachimi SK. Cost-effectiveness of Human Papilloma Virus (HPV) vaccination in Nigeria: a decision analysis using pragmatic parameter estimates for cost and programme coverage. BMC Health Serv Res. 2017;17(1):815.

Cite this article as: Okwe UN, Chime H, Nwose EU. Factors influencing the acceptance of HPV vaccine among civil servants in Delta State Secretariat. Int J Reprod Contracept Obstet Gynecol 2019;8:1227-32. 